\title{
Symptomatic improvement in an acute, non-traumatic spine pain model with a combination of uridine triphosphate, cytidine monophosphate, and hydroxocobalamin
}

\author{
Marco Antonio Mibielli, Carlos Pereira Nunes, Ari Boulanger Scussel Jr., \\ Mendel Suchmacher Neto, Lisa Oliveira, Mauro Geller
}

Teresópolis Medical School-UNIFESO, Rio de Janeiro, Brazil; *Corresponding Author: mgeller@infolink.com.br

Received 11 November 2013; revised 18 December 2013; accepted 8 January 2014

Copyright (C) 2014 Marco Antonio Mibielli et al. This is an open access article distributed under the Creative Commons Attribution License, which permits unrestricted use, distribution, and reproduction in any medium, provided the original work is properly cited. In accordance of the Creative Commons Attribution License all Copyrights (c) 2014 are reserved for SCIRP and the owner of the intellectual property Marco Antonio Mibielli et al. All Copyright (C 2014 are guarded by law and by SCIRP as a guardian.

\section{ABSTRACT}

Rationale: In a previously published trial on spinal acute non-traumatic pain, peripheral neuroregenerative combination of UTP, CMP and hydroxocobalamin presented unexpected analgesic properties. Objective: To corroborate analgesic effects of UTP, CMP and hydroxocobalamin combination in a self-paired evolutionary model. Methods: Mean VAS scores from pretreatment, V2 (5th treatment day) and V3 (10th treatment day) were plotted and statistically analyzed (ANOVA) for differences. PFQ scores from pretreatment, V2, and V3 were analyzed using the chi-square test. Results: The difference between V3 and pretreatment mean VAS scores was statistically significant $(p<0.0001)$. The improvement in PFQ scores throughout the study was found to be statistically significant $(p<0.0001)$. Conclusion: The combination of UTP, CMP and hydroxocobalamin seems to have analgesic properties in medium-term use. The complex peripheral neuroregenerative pharmacodynamics of this combination provides a plausible basis for this finding. Further randomized studies are needed to explore this combination for the indication of neuropathic pain due to spinal structure involvement.

\section{KEYWORDS}

Uridine Triphosphate; Cytidine Monophosphate; Hydroxocobalamin; Analgesia

\section{INTRODUCTION}

In a previously published clinical trial by Mibielli et al., on spinal acute non-traumatic pain [1], carried out in a double-blind comparative manner, the authors randomized a sample of patients with non-traumatic lower back, hip, and neck pain into two groups: 1) group DN $\left(n_{\mathrm{ND}}=40\right)$ - a combination of diclofenac-cholestyramine (equivalent to $70 \mathrm{mg}$ of diclofenac) once daily + two capsules with uridine triphosphate (UTP) $1.5 \mathrm{mg}$, cytidine monophosphate (CMP) $2.5 \mathrm{mg}$, and hydroxocobalamin $1000 \mathrm{mcg}$, thrice daily, and 2) group NB ( $n_{\mathrm{NB}}=$ 41) - two capsules with UTP $1.5 \mathrm{mg}$, CMP $2.5 \mathrm{mg}$, and hydroxocobalamin $1000 \mathrm{mcg}$, thrice daily. Their primary objective was to evaluate the superiority of group DN over group NB, regarding pain visual analog scale (VAS), patient functionality questionnaire (PFQ), and overall efficacy evaluation by the investigating physician. Group DN showed statistically significant better results in all three evaluated endpoints.

The original study reported on the results of a doubleblind, randomized comparative trial comparing the effects of treatment with the combination of diclofenac + CMP + UTP + vitamin B12 versus the combination of only CMP + UTP + vitamin B12. Efficacy measures included a $100 \mathrm{~mm}$ visual analog pain scale, in which each subject placed a vertical mark along a $100 \mathrm{~mm}$ line from $0 \mathrm{~mm}$ on the left side, corresponding to "no pain" to 100 $\mathrm{mm}$ on the right side, corresponding to "most severe pain". The scores were recorded as the distance from the left side of the line $(0 \mathrm{~mm})$ to the subject's mark. The Patient Functionality Questionnaire was also used as an efficacy measure, in which one point was awarded to 
each "Yes" answer to the following questions:

1. Due to the pain in my (lower back/hips/neck):

2. I do not sleep well

3. I have to lie down more often

4. It is difficult for me to get up from my bed or a chair

5. I can stand only for a short while

6. I can walk up stairs only slowly

7. It is difficult for me to wash or dry off my whole body

8. It is difficult for me to put on my clothes

9. I can only walk short distances

10.I try to avoid picking things up from the floor

11.I have to change my posture more often

12. I cannot carry heavy things

13. I have to ask other people for assistance

The authors noticed an unexpected favorable performance of group NB, regarding mean pain VAS endpoint, after publishing their paper. Seemingly, mean VAS score decreased at visit V2 (5th treatment day) in relation to pretreatment levels, and from V3 (10th treatment day) in relation to V2 and to pretreatment levels, in a self-paired fashion. This finding sounded interesting, given that the combination of UTP, CMP and hydroxocobalamin was pharmacologicaly classified as peripheral neuroregenerative, and no analgesic properties were attributed to it in medical literature. A new investigational process was then derived, in order to assess the clinical efficacy responses obtained among the subjects of group NB.

\section{METHODS}

We performed an analysis of previously unpublished data from investigators' files pertaining to the pain VAS and PFQ scores of the patient group treated with the combination of UTP, CMP, and hydroxocobalamin (Group NB). The data was tabulated and statistical evaluation was performed using GraphPad Prism software version 5.04. The VAS score results from Pretreatment, V2 (after 5 days of treatment), and V3 (after 10 days of treatment) were compared using the one-way repeated measures analysis of variance (ANOVA). PFQ scores from Pretreatment, V2, and V3 were analyzed using the chi-square test.

We also performed an updated literature review based on a search of PubMed and SciElo using the search terms "uridine + cytidine + hydroxocobalamin + analgesia", "uridine + analgesia", "cytidine + analgesia", "uridine + cytidine + analgesia" "nucleotides + analgesia", "hydroxocobalamin + analgesia", and "vitamin $\mathrm{B}_{12}+$ analgesia”.

\section{RESULTS}

Briefly, the demographic data of the NB group is summarized in Table 1, reported as $\mathrm{n}$ or mean \pm standard
Table 1. Demographic data.

\begin{tabular}{cc}
\hline Demographic data & Group NB \\
\hline Gender & 17 \\
Female & 24 \\
Male & \\
Ethnicity & 0 \\
Asian & 16 \\
Black & 8 \\
Caucasian & 17 \\
Mulatto & $46.29( \pm 0.908)$ \\
Age (years) & $170.2( \pm 1.261)$ \\
Height (cm) & $74.95( \pm 1.715)$ \\
Weight (kg) & \\
Blood pressure (mmHg) & $123.2( \pm 0.99)$ \\
Systolic & $79.9( \pm 1.294)$ \\
Diastolic & $70.27( \pm 0.849)$ \\
Heart rate (bpm) & 5 \\
Pain location & \\
Knee & 9 \\
Hower back & \\
\hline
\end{tabular}

deviation (SD).

Mean VAS scores at pretreatment in the NB patient group were $59.44 \mathrm{~mm}( \pm 12.43)$. At Visit 2 , mean VAS scores decreased to $42.41 \mathrm{~mm}( \pm 17.66)$, a reduction of $17.03 \mathrm{~mm}$ in mean total score in relation to pretreatment. At Visit 3, mean VAS scores were $30.35 \mathrm{~mm}( \pm 17.51)$, representing a further mean reduction of $12.06 \mathrm{~mm}$ in relation to Visit 2, and a $28.29 \mathrm{~mm}$ reduction in relation to pretreatment values. The difference in mean VAS scores from pretreatment to V3 was statistically significant $(p<0.0001)$ (Figure 1).

At Pretreatment, PFQ score median was 7 points, while at Visit 2, score median decreased to 6 points and at Visit 3, score median was 4 points, indicating an improvement in functionality during the treatment period. The improvement in PFQ scores throughout the study was found to be statistically significant $\left(\chi^{2}=60.74 ; \mathrm{DF}=\right.$ 24; $p<0.0001$ ) (Figure 2).

\section{DISCUSSION}

Pyrimidinic nucleotides UTP and CMP, plus hydroxocobalamin, are available as a peripheral neuroregenerating combination. Pharmacological properties attri- 


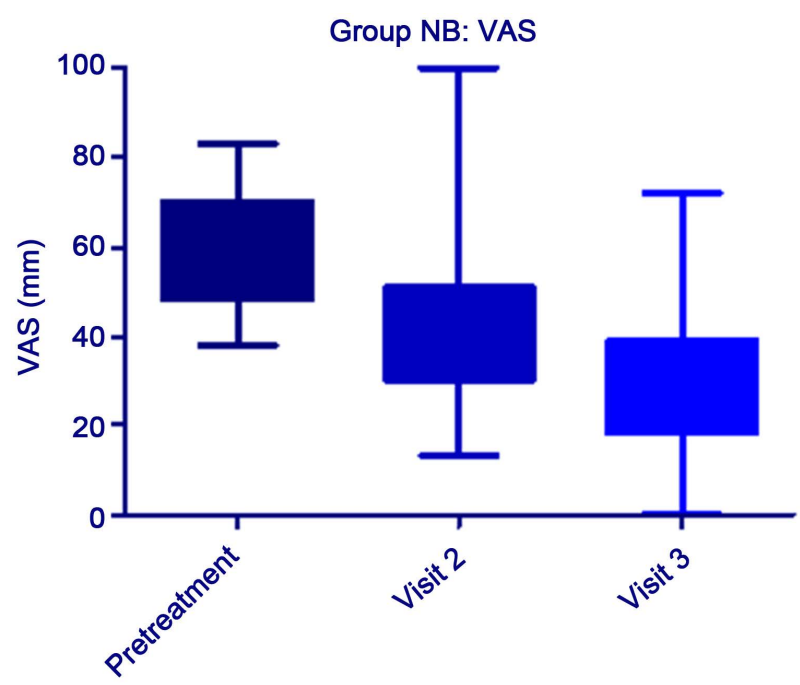

Study Visits

Figure 1. Self-paired evolutionary performance of mean VAS scores in NB group (pretreatment, V2, and V3).

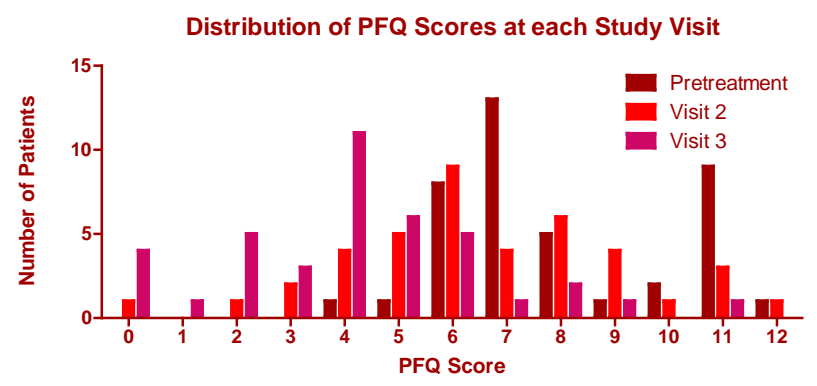

Figure 2. Distribution of Group NB PFQ Scores ranging from 0 (best possible score) to 12 (worst possible score) at Pretreatment, Visit 2, and Visit 3.

buted to these nucleotides are: 1) stimulation of nerve cell protein synthesis, 2) stimulation of nerve cell membrane synthesis, 3) stimulation of myelin sheath synthesis, and 4) neurite sprouting through P2Y receptors stimulation [2-12]. Hydroxocobalamin pharmacodynamics in peripheral nerve insults consists in: 1) stimulation of myelin basic protein (MBP) synthesis, 2) modulation of Prion Particle ${ }^{\text {cellular }}\left(\mathrm{PrP}^{\mathrm{c}}\right)$ levels in Schwann cells, 3) oxidative stress protection to Schwann cells through stimulation of conversion of homocystheine to methionine, and 4) stimulation to methionine synthesis in nerve cells [13-20].

We were not able to find any evidence of direct analgesic properties of UTP, CMP and hydroxocobalamin combination in medical literature. Nevertheless, the pathophysiology of this complex symptom is partially based on the structural compromise of nerve cells, glia and connective tissue of peripheral nerve. If one assumes that the stimulus for tissue regeneration could lead to an anticipated reversion of this process, then neuropathic pain improvement parallel to peripheral nerve restoration becomes a plausible proposition. One can find a correspondence for this assumption in a study published by Goldberg et al. [21]. Actually, the present study partially reproduces the results from this former trial. In this comparative, double blinded study, the authors randomized a sample of patients with spinal and hip structural bone changes complicated with neural compression and neuropathic pain, into two groups: 1) group A-two capsules with UTP $1.5 \mathrm{mg}$, CMP $2.5 \mathrm{mg}$, and hydroxocobalamin $1000 \mathrm{mcg}$, thrice daily, and 2) group B- two capsules of hydroxocobalamin $1000 \mathrm{mcg}$, thrice daily. Results from group A mean VAS scores and SD progression from pretreatment, V2, and V3, are detailed in a selfpaired box-plot graph (Figure 3). The difference between V3 (15) and pretreatment (58) VAS means was statistically significant $(\mathrm{p}<0.0001)$.

In a clinical assessment of patients presenting with alcoholic polyneuropathy, the combination of UTP, CMP and hydroxocobalamin was found to reduce pain, paresthesia, altered motor coordination and altered vibration perception among 120 subjects treated with a 6-day intramuscular injection of: cytidine monophosphate (CMP) $5.0 \mathrm{mg}$; uridine triphosphate (UTP) $3.0 \mathrm{mg}$; hydroxocobalamin $2.0 \mathrm{mg}$; and lidocaine $20 \mathrm{mg}$ (for local pain relief), followed by a 30-day treatment period of thrice daily oral ingestion of: cytidine monophosphate (CMP) $2.5 \mathrm{mg}$; uridine triphosphate (UTP) $1.5 \mathrm{mg}$; hydroxocobalamin $1.0 \mathrm{mg}$ [22].

Regarding analgesic capacity itself, pharmacological properties of two pyrimidinic nucleotides were experimentaly demonstrated by Okada et al.

These investigators developed normal and neuropathic murine pain models, in order to measure analgesic effects

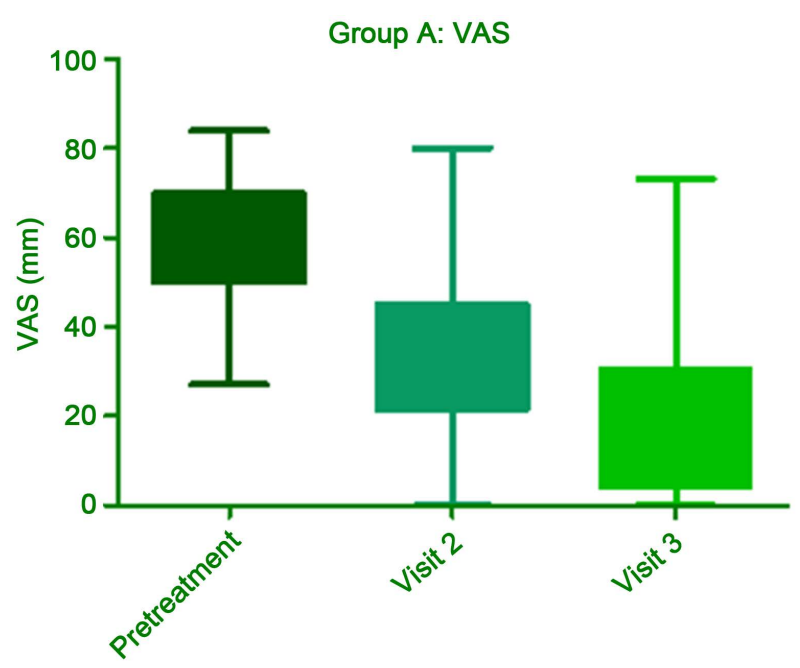

Study Visits

Figure 3. Self-paired evolutionary performance of mean VAS scores in group A (pretreatment, V2, and V3) (graph not present in the original paper; built on data from published tabled results). 
associated to intrathecal administration of UTP and UDP, against a vehicle. These investigators found statistically significant differences favoring UTP and UDP regarding mechanical nociception, thermal nociceptive latency, and allodynia endpoints. The authors concluded that the activation of UTP-sensitive $\mathrm{P}_{2} \mathrm{Y}_{2}$ and/or $\mathrm{P}_{2} \mathrm{Y}_{4}$ receptors produces inhibitory effects on spinal pain transmission [23].

The influence of vitamin $\mathrm{B}_{12}$ in pain relief has been extensively investigated in both the clinical and preclinical settings. In 2004, Granados-Soto et al. reported that administration of vitamin $\mathrm{B}_{12}$ in rats, resulted in a dose-dependent reduction of tactile allodynia induced by spinal nerve ligation [24]. Similar results were reported in a 2008 study at doses of $6 \mathrm{mg} / \mathrm{kg}$ [25]. In a study examining the effects of high doses of vitamin $\mathrm{B}_{12}$ on nerve regeneration rates in a rat model of acrylamide neuropathy, methylcobalamin doses of 500 micrograms $/ \mathrm{kg}$ resulted in significantly faster recovery rate in compound muscle action potentials after tibial nerve stimulation compared to a saline-treated control group [26].

Vitamin $B_{12}$ has shown clinical efficacy in the treatment of diabetic neuropathy. The effects of high-dose intravenous administration of the vitamin $\mathrm{B}_{12}$ analog methylcobalamin (500 $\mu \mathrm{g} 3$ times per week) over a 6month period was evaluated in chronic hemodialysis patients presenting diabetic neuropathy. The authors reported reduction in pain and paresthesia along with significant improvement of ulnar motor and median nerve conduction velocities [27]. Methylcobalamin was also shown to be effective in the treatment of diabetic neuropathy at oral doses of $500 \mathrm{mg}$; treatment resulted in improvement in pain as well as somatosensory and autonomic symptoms [28,29]. Mauro et al. (2000) assessed the efficacy of intramuscular vitamin $\mathrm{B}_{12}$ in the treatment of low back pain in patients presenting mechanical or irritative lumbago, reporting that after a 2-week treatment period consisting of once-daily $1000 \mathrm{mg}$ vitamin $\mathrm{B}_{12}$ injections, treated subjects experienced a significant decrease in pain and disability that was statistically superior to the placebo-treated control group [30].

The results of the above-mentioned studies indicate the following mechanisms of action for vitamin $\mathrm{B}_{12}$ activity in pain relief: promotion of nerve regeneration and/ or remyelination by accumulation of exogenous $B_{12}$ [30]; because vitamin $\mathrm{B}_{12}$ may act as a methyl donor in DNA metabolism, high concentrations upregulate gene transcription, increasing protein synthesis for nerve regeneration [31]. Additionally, Takeshige et al. (1971) suggested a selective blockade of sensory nerve conduction as a mechanism of action for vitamin $\mathrm{B}_{12}$ in painful conditions [32].

\section{CONCLUSION}

Combination of UTP, CMP and hydroxocobalamin seems to present analgesic effects in peripheral neuropathic pain secondary to spine structural disorders, in mediumterm use. These properties can be attributed to a complex pharmacodynamics involving indirect (nerve cell protein synthesis, myelin sheath synthesis, MPB synthesis, etc), as well as direct (P2Y receptors stimulation) mechanisms. Further studies are needed to corroborate these findings, as well as to better establish the temporal relationship between the combination administration and significant levels of pain improvement.

\section{REFERENCES}

[1] Mibielli, M.A., Nunes, C.P., Cohen, J.C., Júnior, A.B.S., Higashi, R., Bendavit, G.G., Oliveira, L. and Geller, M. (2010) Treament of acute, non-traumatic pain using a combination of diclofenac-cholestyramine, uridine triphosphate, cytidine monophosphate, and hydroxocobalamin. Proceedings of the Western Pharmacology Society, 53, 512.

[2] Wattig, B., Schalow, G., Heydenreich, F., Warzok, R. and Cervós-Navarro, J. (1992) Enhancement of nerve fibre regeneration by nucleotides after peripheral nerve crush damage. Electrophysiologic and morphometric investigations. Arzneimittelforschung, 42, 1075-1078.

[3] Wattig, B., Schalow, G., Madauss, M., Heydenreich, F., Warzok, R. and Cervós-Navarro, J. (1992) Acceleration of nerve and muscle regeneration by administration of nucleotides-Electroneurophysiological and morphometrical investigations. Acta Histochemica, 42, 333-339.

[4] Wattig, B., Schalow, G., Madauss, M., Heydenreich, F., Warzok, R. and Cervós-Navarro, J. (1991) Acceleration of muscle regeneration by nucleotide administration. Experimental morphometric studies. Zentralbl Pathol, 137, 409-413.

[5] Wattig, B., Schalow, G., Heydenreich, F., Schalow, G., Radzewitz, B., Warzok, R. and Cervós-Navarro, J. (1991) Nucleotide beschleunigen die nervenregeneration (tradução: Nucleotídeos aceleram a regeneração neural). $Z$ Klin Med, 46, 1371-1373.

[6] Pooler, A.M., Guez, D.H., Benedictus, R. and Wurtman, R.J. (2005) Uridine enhances neurite outgrowth in nerve growth factor-differentiated pheochromocytoma cells. $\mathrm{Neu}$ roscience, 134, 207-214.

http://dx.doi.org/10.1016/j.neuroscience.2005.03.050

[7] Neary, J.T., Rathbone, M.P., Cattabeni, F., Abbracchio, M.P. and Burnstock, G. (1996) Trophic actions of extracellular nucleotides and nucleosides on glial and neuronal cells. Trends in Neuroscience, 19, 13-18. http://dx.doi.org/10.1016/0166-2236(96)81861-3

[8] Silei, V., Politi, V. and Lauro, G.M. (2000) Uridine induces differentiation in human neuroblastoma cells via protein kinase C epsilon. Journal of Neuroscience Research, 61, 206-211. http://dx.doi.org/10.1002/1097-4547(20000715)61:2<206 :AID-JNR11>3.0.CO;2-B

[9] Connolly, G.P. and Duley, J.A. (1999) Uridine and its nucleotides: Biological actions, therapeutic potentials. Trends 
in Pharmacology Sciences, 1, 218-225. http://dx.doi.org/10.1016/S0165-6147(99)01298-5

[10] Webb, T.E. and Barnard, E.A. (1999) Molecular biology of P2Y receptors expressed in the nervous system. Progress in Brain Research, 120, 23-31. http://dx.doi.org/10.1016/S0079-6123(08)63543-8

[11] Hussl, S. and Boehm, S. (2006) Functions of neuronal P2Y receptors. Pflügers Archiv, 452, 538-551. http://dx.doi.org/10.1007/s00424-006-0063-8

[12] Illes, P. and Zimmerman, H. (1999) Nucleotides and their receptors in the nervous system. Progress in Brain Research, 120.

[13] Guéant, J.-L. (2012) Novel aspects of molecular and cellular effects of vitamin B12. Vitamin B12 Symposium, University of Lorraine, Lorraine.

[14] Scalabrino, G. (2012) Cobalamin and normal prions: New horizons for cobalamin neurobiology. Vitamin B12 Symposium, University of Lorraine, Lorraine.

[15] Cyanocobalamin (2010) Drugdex drug evaluations. Micromedex.

[16] Hendler, S.S. (2008) PDR for nutrional supplements. 2nd edition, Thomson Reuters.

[17] Goodman and Gilman's (2011) The pharmacological basis of therapeutics. 12th edition, McGraw Hill.

[18] Voet, D., Voet, J.G. and Pratt, C.W. (2002) Fundamentos de bioquímica. Artmed Editora.

[19] Cazaubon, S., Viegas, P. and Couraud, P.O. (2007) Functions of prion protein PrPc. Medicine Sciences (Paris), 23, 741-745. http://dx.doi.org/10.1051/medsci/20072389741

[20] McCaddon, A. (2012) Vitamin B12 in neurology and aging: Clinical and genetic aspects. Vitamin B12 Symposium, University of Lorraine, Lorraine.

[21] Goldberg, H., Júnior, A.B.S., Cohen, J.C., Rzetelna, H., Mezitis, S.G.E., Nunes, F.P., Ozeri, D., Daher, J.P.L., Nunes, C.P., Oliveira, L. and Geller, M. (2009) Neural compression-induced neuralgias: Clinical evaluation of the effect of nucleotides associated with vitamin B12. Revista Brasileira de Medicina do Esporte, 66, 380-385.

[22] Geller et al. (2013) Unpublished data.

[23] Okada, M., Nakagawa, T., Minami, M. and Satoh, M. (2002) Analgesic effects of intrathecal administration of P2Y nucleotide receptors agonists UTP and UDP in normal and neuropathic pain model rats. Journal of Pharmacology and Experimental Therapeutics, 303, 66-73. http://dx.doi.org/10.1124/jpet.102.036079

[24] Granados-Soto, V., Sánchez-Ramirez, G., la Torre, M.R., Caram-Salas, N.L., Medina-Santillán, R. and Reyes-Garcia,
G. (2004) Effect of diclofenac on the antiallodynic activity of vitamin B12 in a neuropathic pain model in the rat. Proceedings of the Western Pharmacology Society, 47, 92-94.

[25] Mixcoatl-Zecuatl, T., Quinonez-Bastidas, G.N., CaramSalas, N.L., Ambriz-Tututi, M., Araiza-Saldana, C.I., Rocha-Gonzalez, H.I., Medina-Santillan, R., Reyes-Garcia, G. and Granados-Soto, V. (2008) Synergistic antiallodynic interaciton between gabapentin or carbamazepine and either benfotiamine or cyanocobalamin in neuropathic rats. Methods \& Findings in Experimental \& Clinical Pharmacology, 30, 1-11. http://dx.doi.org/10.1358/mf.2008.30.6.1254247

[26] Wantanabe, T., Kaji, R., Oka, N., Bara, W. and Kimura, J. (1994) Ultra-high dose methylcobalamin promotes nerve regeneration in experimental acrylamide neuropathy. Journal of the Neurological Sciences, 122, 140-143. http://dx.doi.org/10.1016/0022-510X(94)90290-9

[27] Kuwabara, S., Nakazawa, R., Azuma, N., Suzuki, M., Miyajima, K., Fukutake, T. and Hattori, T. (1999) Intravenous methylcobalamin treatment for uremic and diabetic neuropathy in chronic hemodialysis patients. Internal Medicine, 38, 472-475.

http://dx.doi.org/10.2169/internalmedicine.38.472

[28] Yaqub, B.A., Siddique, A., Sulimani, R. (1992) Effects of methylcobalamin on diabetic neuropathy. Clinical Neurology and Neurosurgery, 94, 105-111. http://dx.doi.org/10.1016/0303-8467(92)90066-C

[29] Devathasan, G., Teo, W.L. and Mylvaganam, A. (1986) Methylcobalamin in chronic diabetic neuropathy. A doubleblind clinical and electrophysiological study. Journal of Clinical Trials, 23, 130-140.

[30] Mauro, G.L., Martorana, U., Cataldo, P., Brancato, G. and Letizia, G. (2000) Vitamin B12 in low back pain: A randomised, double-blind, placebo-controlled study. European Review for Medical and Pharmacological Sciences, 4, 53-58.

[31] Pfohl-Leszkowicz, A., Keith, G. and Dirheimer, G. (1991) Effect of cobalamin derivatives on in vitro enzymatic DNA methylation: Methylcobalamin can act as a methyl donor. Biochemistry, 30, 8045-8051. http://dx.doi.org/10.1021/bi00246a024

[32] Takeshige, C., Ando, Y. and Ando, M. (1971) Effects of vitamin B12 and aldosterone on the conduction of sensory and motor nerve impulse. Vitamins (Japan), 44, 272282. 